\title{
Juazeiro iconográfico: da linguagem visual aos ícones da cidade
}

\author{
Elane Abreu de Oliveira' \\ Joedson Oliveira ${ }^{2}$ \\ Luan Duarte ${ }^{3}$ \\ Romênia Oliveira ${ }^{4}$ \\ Thamyres Souza ${ }^{5}$
}

\section{Resumo}

Este trabalho discute a capacidade comunicativa do visual, entendendo-o como campo de conhecimento permeado por signos e mensagens socialmente praticados. Em Juazeiro do Norte - CE, a marca da Prefeitura é exemplo de uma prática visual comunicativa desencadeada por sua composição com elementos icônicos da cidade. Com o objetivo de analisar a linguagem visual e a representatividade dos lugares utilizados, foi feita uma pesquisa exploratória de marcas similares a de Juazeiro do Norte e uma análise dos elementos que compõem a marca da cidade. A reunião dos signos visuais apresentados ressalta que a representação da cidade está fincada principalmente em ícones da arquitetura e da religiosidade, o que comunica o valor destas visualidades para a imagem urbana.

Palavras-chave: comunicação visual, representação iconográfica, Juazeiro do Norte.

\begin{abstract}
This paper discusses communicative capacity of the visual, understanding it as a field of knowledge permeated by socially practiced signs and messages. In Juazeiro do Norte (Ceará), the city hall brand is an example of a communicative visual practice triggered by its composition based on city iconic elements. With the objective of analyzing visual language and used places' representativity, an exploratory research of similar brands to Juazeiro do Norte one and an analysis of elements that make up the city brand were done. The presented combination of visual signs highlights that city representation is more important in terms of architecture and religiosity, which communicates visualities' value for the urban image.
\end{abstract}

Keywords: visual communication, iconographic representation, Juazeiro do Norte.

\footnotetext{
1 Professora do Curso de Jornalismo da Universidade Federal do Cariri. Doutora em Comunicação e Cultura pela UFRJ. elane.abreu@ufca.edu.br

2 Graduando em Jornalismo. Universidade Federal do Cariri. joedson2013@gmail.com

3 Graduando em Jornalismo. Universidade Federal do Cariri. Iuanduarter@outlook.com

4 Graduanda em Jornalismo. Universidade Federal do Cariri. romenia.go@gmail.com

5 Graduanda em Jornalismo. Universidade Federal do Cariri.souza_thamyres@hotmail.com
} 


\section{VOZES \\ ¿'DIÁLOGO}

Itajaí, v. 17, n. 02, jul./dez. 2018

\section{Introdução}

Este trabalho surge da inquietação diante da nova marca $(\operatorname{logo})$ da prefeitura de Juazeiro do Norte-CE, lançada em 2017: como a cidade aparece representada por meio da seleção de cinco ícones urbanos? Esta pergunta foi um dos pontos de partida de um projeto de pesquisa que abrange questões sobre a comunicação urbana e visual da cidade. Dentro do escopo desse projeto, a primeira fase foi dedicada a investigar como se deu a construção dessa nova identidade visual da Prefeitura da cidade de Juazeiro por meio de entrevistas com a assessora de comunicação do órgão e com o designer responsável pela criação da marca. Através das respostas, partimos para a pesquisa exploratória de marcas governamentais de cidades do Brasil e, em seguida, para uma análise específica da marca da atual gestão da cidade de Juazeiro do Norte.

Situada no sul do estado do Ceará, Juazeiro do Norte é recorrentemente lembrada pela representação icônica de Padre Cícero, figura emblemática na formação da cidade e até hoje consagrada pela devoção popular. Inúmeras são as apropriações da imagem do "Padim", que dá forma a um monumento construído em grande escala na parte alta da cidade, no bairro do Horto. Réplicas com a sua imagem estão espalhadas no comércio, nas vendas informais e nos lares dos devotos. Essa força icônica é culturalmente praticada por quem habita o lugar e também por quem deseja levar dele uma lembrança. Por outro lado, a marca institucional da Prefeitura traz Padre Cícero como elemento iconográfico, no entanto, ao lado dele, são colocados outros elementos urbanos menos afamados e difundidos. Neste sentido, uma nova construção de identidade visual urbana entra em jogo, uma vez que outros reconhecimentos são convocados pela memória da marca: as formas arquitetônicas da Capela de Nossa Senhora do Socorro, do Memorial Padre Cícero, do Luzeiro do Sertão e do Unique Condominium.

Com base nos estudos da linguagem visual de Dondis (2003) e nas formulações de Barthes $(2012$, 2005), situaremos teoricamente as mensagens visuais em jogo na marca governamental em diálogo com autores que se dedicaram ao estudo empírico e historiográfico de Juazeiro do Norte - CE. Apresentaremos, em seguida, a análise e discussão dos resultados, especificamente sobre o repertório iconográfico levantado com base nas características da identidade visual da Prefeitura. A interpretação desse material busca ressaltar os ícones instituídos como traços da cidade seja na perspectiva de seus aspectos gráficos, seja na relação deles com o repertório de lugares selecionados do espaço urbano.

\section{Linguagem visual e a imagem icônica de Juazeiro do Norte}

A visão permite dar sentido e valor às coisas que nos cercam. Através do "ver", são vislumbrados detalhes e características únicas que dão significações a tudo que nos rodeia. 


\section{VOZES $_{\& \text { DIÁLORO }}^{\mid}$}

Itajaí, v. 17, n. 02, jul./dez. 2018

Nessa lógica, entendemos que a sociedade vive as práticas trazidas pela imagem, seja em ritos, ocasiões ou vivências diversas. Os objetos adquirem ou perdem valores de acordo com as praxes dos indivíduos em geral. Conceitua-se assim o visual, capaz de transmitir conhecimento e informações, e que na atualidade adquire valor tão fundamental que se hibridiza com o espaço do verbal. Conforme a comunicação humana se transforma, surgem sistemas de comunicação que medeiam nossa aproximação com a realidade, configurando-se em práticas na sociedade.

Segundo Barthes (2005), a difusão de imagens (pertencente ao mundo moderno) e o poder representacional que elas possuem são produto da sociedade tecnológica. Esse corpo social produz e consome incansavelmente mensagens visuais e, muitas vezes, essa produção aparece sem saciedade, gerando liquidez e pouco processo reflexivo sobre o que é visto. Por outro lado, Dondis (2003) acredita que amplificar nossa capacidade de ver significa expandir a habilidade de entender uma mensagem visual, e, o que é ainda mais importante, de criar uma mensagem visual. É certo que a visão envolve algo mais do que o mero fato de ver ou de que algo nos seja mostrado. É parte integrante do processo de comunicação, que abrange todas as considerações relativas às belas-artes, às artes aplicadas, à expressão subjetiva e à resposta a um objetivo funcional.

Através dessa percepção, surge o alfabetismo visual, com o objetivo de "construir um sistema básico para a aprendizagem, a identificação, a criação e a compreensão de mensagens visuais que sejam acessíveis a todas as pessoas” (DONDIS 2003, p. 4). Ele possibilita uma desmontagem e remontagem das imagens, concebendo uma série de percepções sobre o que está sendo observado. Além disso, constitui todo um corpo de dados, usados para compreender mensagens em diversos níveis de utilidade, ou seja, desse sistema há subgrupos e divisões que facilitam a significação do conteúdo. Esses grupos se separam em três partes, que exporemos a seguir. A compreensão primordial se dedica aos elementos básicos da comunicação visual, que compõem a substância da mensagem e podem ser desmembrados com a finalidade de analisar o que é expresso. Para Dondis (2003), eles são considerados a caixa de ferramenta de todas as comunicações visuais:

(...) a fonte compositiva de todo tipo de materiais e mensagens visuais, além de objetos e experiências: o ponto, a unidade visual mínima, o indicador e marcador de espaço; a linha, o articulador fluido e incansável da forma, seja na soltura vacilante do esboço seja na rigidez de um projeto técnico; a forma, as formas básicas, o círculo, o quadrado, o triângulo e todas as suas infinitas variações, combinações, permutações de planos e dimensões; a direção, o impulso de movimento que incorpora e reflete o caráter das formas básicas, circulares, diagonais, perpendiculares; o tom, a presença ou a ausência de luz, através da qual enxergamos; a cor, a contraparte do tom com o acréscimo do componente cromático, o elemento visual mais expressivo e emocional; a textura, óptica ou tátil, o caráter de superfície dos materiais visuais; a escala ou proporção, a medida e o tamanho relativos; a dimensão e o 


\section{VOZES $_{\text {\&IÁLORO }}^{\mid}$}

Itajaí, v. 17, n. 02, jul./dez. 2018

movimento, ambos implícitos e expressos com a mesma frequência (DONDIS, 2003, p.13).

As imagens, sendo desse modo formadas, se expressam e se decodificam em três níveis que se sobrepõem, mas também se interligam. O primeiro é o da representação. Neste os elementos da realidade são expostos no plano bidimensional da forma mais realista possível. Ele é governado pela experiência direta e atua na mais estreita ligação com a realidade de nosso ambiente. Nele, objetiva-se relacionar o elemento representado facilmente com o real.

Entendendo essa conceituação, compreendemos as imagens fotográficas do Padre Cícero como uma das representações mais fortemente associadas à cidade de Juazeiro do Norte, pois esse personagem acabou sendo um contribuinte para a formação e expansão do município, além de ser transformador da região nos quesitos religiosidade e cultura. As imagens do Padre ainda em vida se associam com o real e dão essa proximidade de representação.

Conforme Araújo (2011), existem diferentes formas de representar esse personagem, desde as manifestações das "elites” até as camadas mais populares, numa combinação de democracia com relações arcaicas de poder. Mesmo após a morte, a imagem do Padre Cícero representa a sua presença na cidade, impulsionando a economia local através da produção de estátuas de gesso e madeira, confeccionadas em diferentes tamanhos pelos "artesãos do Padrinho".

Percebemos assim a figura do Padre Cícero no caráter de representação da cidade, sendo que as percepções de cada ser são individuais e sofrem alterações de acordo com o grupo e nível de interesse no objeto (a figura do padre). Para Dondis (2003), no nível representacional, não se faz necessária a intervenção de nenhum sistema de códigos para facilitar a compreensão, e de nenhuma decodificação que retarde o entendimento. Às vezes basta ver um processo para compreender como ele funciona. Em outras palavras, o nível representacional possibilita a comunicação direta do objeto, sem necessidade de uma descrição verbal.

O segundo nível é o do simbolismo, em que há a redução dos elementos da realidade às suas formas mais básicas. É importante que o receptor reconheça o que é exposto, mas não é necessário que haja uma fidelidade com os detalhes. Além de ser caracterizado por uma simplificação do que é representado, podem ser identificadas ações ou organizações, estados de espírito, direções. A imagem do Padre Cícero também é simbólica, de tal forma que há uma comercialização em larga escala desse material simbólico. Em outras palavras, o culto ao Padre está associado a objetos simbólicos produzidos e comercializados nos circuitos das romarias e imediações dos lugares sagrados, como estátuas, terços, xilogravuras, dentre outros. Além disso, o Padre Cícero representa o maior capital simbólico da cidade de Juazeiro do Norte, sendo referência na Região Metropolitana do Cariri, entendendo o simbólico conforme aponta Maria Araújo (2011). 


\section{VOZES $_{\text {\&IÁLORO }}^{\mid}$}

Itajaí, v. 17, n. 02, jul./dez. 2018

Isso quer dizer que há uma apropriação coletiva por diferentes atores sociais, políticos e agentes econômicos em relação à simbologia desse personagem em diferentes níveis, individuais e grupais. Isso influencia diretamente na economia do local, onde "os bens simbólicos acabam sendo produzidos levando em consideração o imaginário de seus consumidores, os devotos e os romeiros" (ARAÚJO, 2011, p.51).

O terceiro e último nível da mensagem visual é o da abstração, em que os elementos representados tanto podem manter a mínima relação com o real, como podem se desvincular da realidade. Nesta classificação se encaixa qualquer criação da mente humana que não possua um referencial fiel na natureza. "Talvez ele seja o mais difícil de descrever, e pode vir a tornar-se o mais importante para o desenvolvimento do alfabetismo visual." (DONDIS, 2003, p. 12). Além disso, o abstrato vai se fundir de maneira mais individual, através das percepções de cada um.

A partir do reconhecimento desses três níveis da linguagem - representacional, simbólico e abstrato - é possível refletir que o Padre Cícero é um signo que se apresenta tanto como ícone (as estátuas, fotos e pinturas que o representam remetem ao homem que existiu, mas não é a pessoa em si), quanto como símbolo (pelo seu reconhecimento coletivo e importância social na cidade). Abstrações dele são também recorrentemente encontradas em formas comerciais e artesanais. Lira Neto, jornalista, escritor brasileiro e biógrafo do Padre Cícero acrescenta:

Para muitos dos milhões de peregrinos que chegam hoje a Juazeiro do Norte, essa é a verdadeira história do nascimento do padre Cícero. Ele seria a reencarnação do próprio Cristo. A imaginação coletiva, disseminada de boca em boca e de geração em geração, encarregou-se de atribuir uma origem sagrada, não carnal, ao protetor dos romeiros (NETO, 2009, p. 23)

Percebe-se assim que a figura do Padre Cícero se expressa nos três níveis da linguagem visual, de formas diferentes. Esse personagem é ressignificado através de simbologias, representações e abstrações, seja da sua imagem, dos seus feitos ou do seu legado. Além do mais, há uma dinâmica do sagrado em Juazeiro, que permite que o Padre e a cidade não se desvinculem, um sendo referencial para o outro, numa relação em que ambos são símbolos diferentes, com significados que se interligam.

Desse modo, entendemos que as representações visuais são capazes de produzir signos, que são caracterizados como elementos que desencadeiam processos de significação e que, embora sejam mediados pelos sentidos, manifestam-se no pensamento. Eles são compostos pela junção do significado e do significante, termos fundamentais na constituição do signo. Para Barthes (2012) os significantes constituem o plano da expressão, enquanto os significados constituem o plano do conteúdo. Enquanto a expressão se relaciona com a forma, conceituada como o que pode ser descrito de modo simples pela linguística, o conteúdo está relacionado à substância que é definida como o conjunto dos 


\section{VOZES $_{\text {\&IÁLORO }}^{\mid}$}

Itajaí, v. 17, n. 02, jul./dez. 2018

fenômenos linguísticos que não podem ser descritos sem recorrermos a premissas extralinguísticas.

O significado é aquilo que podemos representar do signo. É a imagem mental que nos é exposta quando estamos diante de algum evento dotado de significação, mas também é o que pode ser expresso sobre tal. Ele é um mediador, a forma daquilo que é dito, entre o signo e o significante, que é a própria coisa, a materialidade do signo em questão. Embora seja de difícil compreensão nesta tentativa de escrita, o pensamento desencadeia esse processo espontaneamente. A cadeia de significados que permeia um signo é composta por uma diversidade de definições que não se limitam à percepção de um único indivíduo. Enquanto Juazeiro do Norte possui seu significado intimamente relacionado ao Padre Cícero - sendo este um processo imagético espontâneo -, há representações sígnicas que variam conforme as construções sociais, os indivíduos e todos os elementos do imaginário que se compõem na vivência urbana.

Os signos são unidades relevantes que, ainda que tenham sido criados por determinada sociedade, acabam adquirindo um poder tão forte que, por vezes, o mesmo grupo que os origina possui dificuldades em enxergá-lo como invenção. Na prática, no imaginário dos romeiros, por exemplo, Padre Cícero é santo; Juazeiro é a cidade do Padre e protegida por Nossa Senhora das Dores.

No campo semiótico existem os ícones, que são caracterizados por serem signos visuais (imagens) que representam um objeto ou coisa por semelhança, já que possuem as mesmas características do objeto. Um ícone usa forma, cor, som, textura e outros elementos sensoriais para criar uma conexão evidente entre imagem e objeto. Eles dependem, em diferentes graus, das convenções culturais. Em suma, ganham uma relação de semelhança com o que representam. Um exemplo relevante é a logo atual da Prefeitura de Juazeiro do Norte, pois ela é repleta de ícones da cidade, compondo a representação visual eleita dela. Cada um tem sua particularidade e acaba remetendo a um recorte do espaço urbano de importância significativa para a prefeitura. De certo modo, eles tentam dialogar entre si na marca e expõem elementos fundamentais da cidade para construção de uma memória iconográfica urbana, manifestada visualmente pela religiosidade e pela arquitetura.

\section{Juazeiro iconográfico: análise visual e relações com a representação urbana}

Percebemos que a construção da nova identidade visual da Prefeitura de Juazeiro do Norte e de sua marca se dá por meio de um ciclo entre religião, história e o contexto atual de desenvolvimento sócio-econômico-cultural da cidade. Os ícones eleitos são marcos visuais importantes para a cidade, sem esquecer, porém, que um deles foi construído recentemente - o Unique Condominium, com obras iniciadas em 2013. 


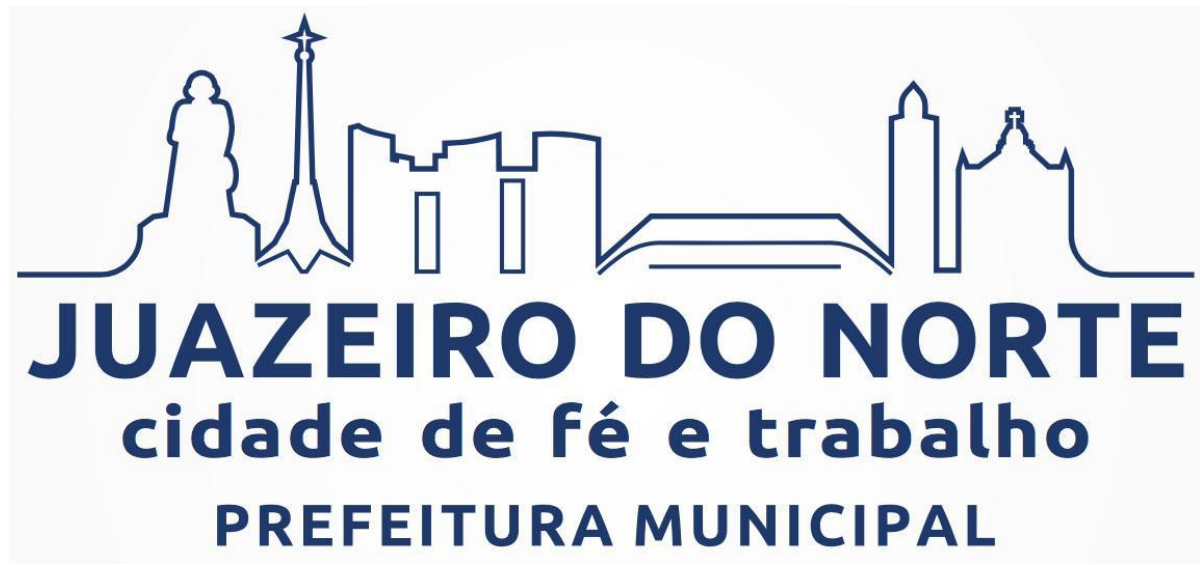

Fonte: site da prefeitura.

O primeiro passo analítico do estudo da marca da prefeitura se deu pela pesquisa de outras marcas governamentais semelhantes a de Juazeiro do Norte, segmentadas em eixos como arquitetura e religião. Esse passo foi determinante para entender as similaridades presentes nas logos pesquisadas e compreender que os artifícios da representação urbana não são únicos e exclusivos de Juazeiro. $\mathrm{O}$ segundo momento analítico partiu da visita aos lugares tornados ícones na marca institucional da prefeitura, que são: Estátua do Padre Cícero, Luzeiro do Sertão, Unique Condominium, Memorial do Padre Cícero e a Capela de Nossa Senhora do Socorro. Todos são pontos de notável importância visual na cidade, devido à sua escala (tamanho) na paisagem, bem como à ligação significativa à imagem de Padre Cícero. A visita foi importante para fotografar os lugares e ter deles uma imagem representacional (DONDIS, 2003).

Percebemos que três dos ícones apresentados na marca estão ligados à figura do Padre Cícero, exceto o Luzeiro do Sertão e o Unique Condominium. Para corroborar tal percepção, a própria mensagem trazida na linguagem verbal da logo, a qual carrega o binômio "trabalho e fé", segundo a assessora de comunicação da prefeitura, é um lema que foi trazido historicamente pelo Padre Cícero para Juazeiro do Norte. Religião e desenvolvimento econômico não se separam, pois tais características estão intrinsecamente associadas nas representações iconográficas. A partir do cenário de cidade que se reconfigura anualmente pelo fluxo de milhares de pessoas que participam das romarias, visitam a cidade e movimentam socioeconomicamente Juazeiro, a logo foi pensada e construída para traduzir visualmente o lugar através dos símbolos pautados no ciclo religião, arquitetura e economia.

Na marca atual estão presentes alguns elementos e níveis da linguagem visual. A linha é um dos elementos com notória e primordial identificação. A partir dela, os ícones que representam a cidade são contornados e dão a impressão de que estão interligados como uma só figura. A linha é trabalhada na marca em forma de contorno, realizando uma 


\section{VOZES}

Itajaí, v. 17, n. 02, jul./dez. 2018

abstração, na qual se torna possível a identificação de cada um dos lugares representados (Figura 1). Outro elemento visual de possível identificação na marca é a cor, trabalhada predominantemente no azul. Esta escolha, segundo a assessoria de comunicação da prefeitura municipal de Juazeiro, foi feita com o intuito de não "agredir" visualmente. Nesse sentido, fazendo paralelo a Dondis (2003), é válido dizer que "a cor tem maiores afinidades com as emoções”. O uso da cor azul na construção da marca governamental sugere sobriedade.

Ao pesquisarmos marcas institucionais de outras cidades e regiões do país (em torno de quinze logos), percebemos que a da Prefeitura de Juazeiro do Norte não é pioneira na forma como apresenta a sua marca oficial. Uma marca governamental muito semelhante quanto à proximidade da forma arquitetônica é a da cidade de Aparecida do Norte - SP. A utilização de lugares religiosos como a igreja é algo em comum entre as duas cidades. Além disso, ambas as marcas são construídas a partir da linha, elemento visual predominante, que realiza um contorno, uniformizando a identificação dos lugares que são representados. Já na marca de Triunfo - PE, percebemos uma totalidade do ícone religioso, que é a Igreja de Nossa Senhora das Dores, coincidentemente o mesmo nome de uma igreja importante de Juazeiro do Norte, ponto turístico em época de romaria, mas que não comparece na logo (Quadro 1).

Quadro 1: Comparativo com marcas das prefeituras de Aparecida do Norte - SP, de Triunfo - PE e de Juazeiro do Norte - CE, respectivamente.

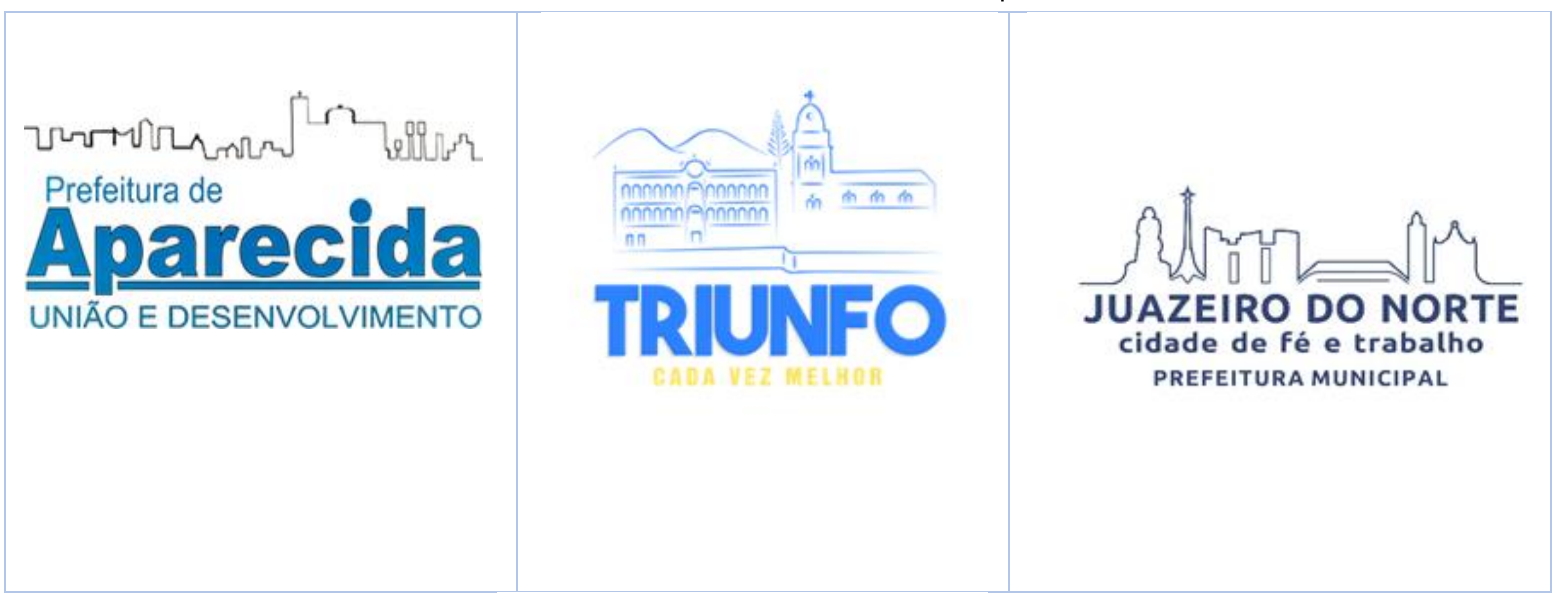

Fontes: sites das prefeituras.

A partir da pesquisa que realizamos, vários outros governos trabalham em sua identidade visual a representação de lugares importantes de suas respectivas cidades no que diz respeito ao desenvolvimento socioeconômico, histórico e cultural de cada uma delas. A representatividade de templos religiosos é um marco presente em quase todas as marcas governamentais pesquisadas. $\mathrm{O}$ uso da cor azul e do traço também se destaca nas marcas construídas. 


\section{VOZES

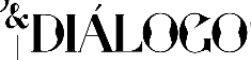

Itajaí, v. 17, n. 02, jul./dez. 2018

Abaixo (Quadro 2) é mostrado um quadro comparativo entre os ícones criados para a atual marca governamental de Juazeiro do Norte e as fotografias realizadas durante as visitas aos espaços representados. A percepção visual durante as visitas ajuda a entender melhor como se dá o processo de simplificação de elementos realistas. Observamos que ver os ícones em seus locais específicos na cidade contribui para ressaltar a diferença de escala e de outros elementos visuais entre signos realistas e abstratos.

Quadro 2: Comparativo dos ícones da marca da

Prefeitura de Juazeiro do Norte-CE.

Padre Cícero




\section{VOZES $_{\text {\&IÁLORO }}^{\mid}$}

Itajaí, v. 17, n. 02, jul./dez. 2018

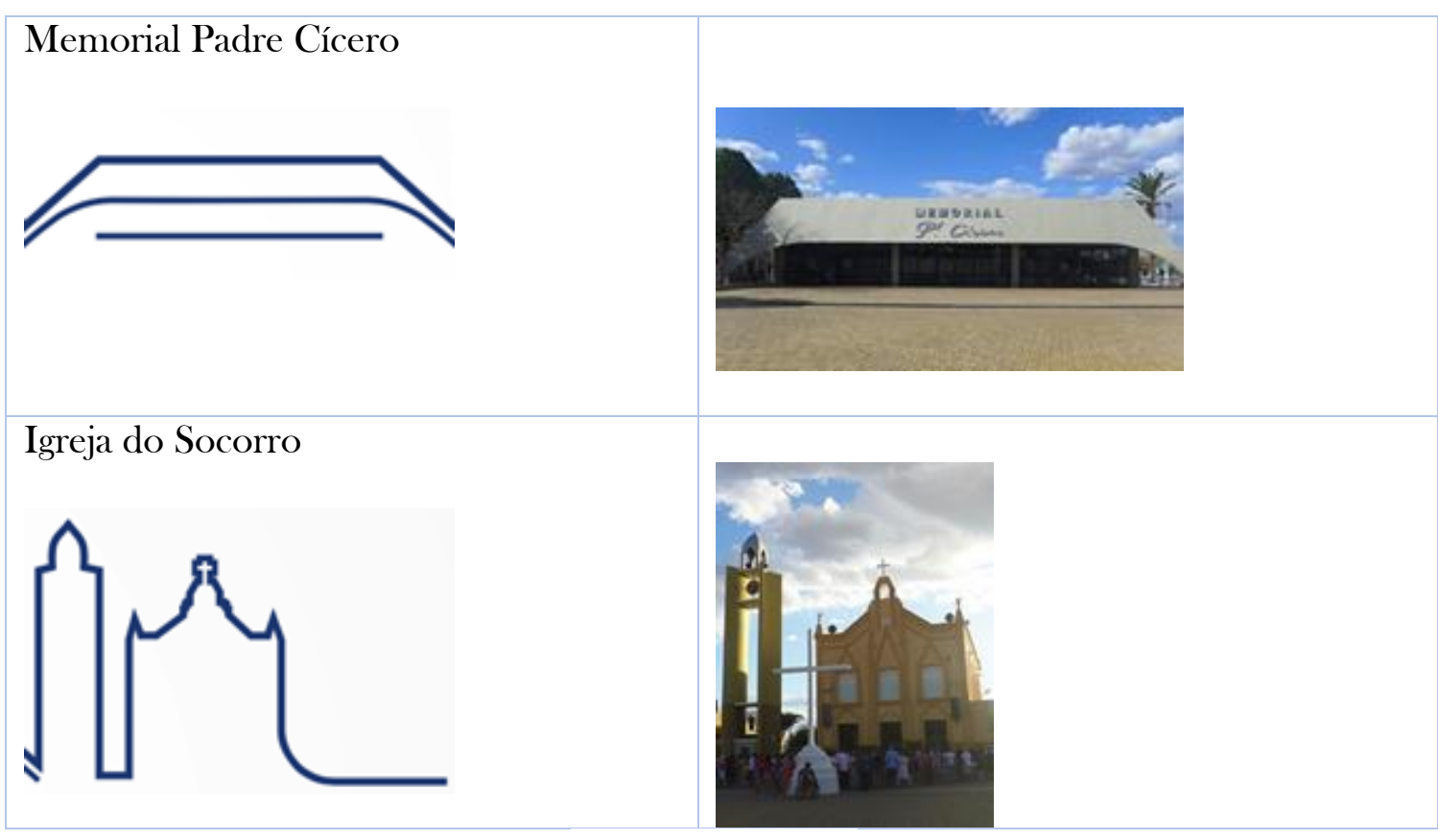

Fonte: os autores

A estátua do Padre Cícero, localizada no alto da Serra do Catolé ou Colina do Horto, como é popularmente conhecida, é um monumento de grande porte e principal expoente visual quando se fala em Juazeiro do Norte. A estátua foi inaugurada em 1969, conta com 27 metros de altura e simboliza não somente a imagem do Padre em vida, mas também traz a ideia de comando do mesmo sobre a cidade por conta da grande altitude em que se encontra localizada. Pintada inteiramente de cor branca, a imagem contraria a versão do "Padim" em vida registrada principalmente em fotografias, nas quais ele se encontra vestido numa batina e com um chapéu de cor preta. Comparando a fotografia do quadro com a marca governamental da cidade, uma grande semelhança é notada: a silhueta branca ou o vazio da forma permanece predominante.

O Luzeiro do Sertão é uma torre metálica de 111,5 metros de altura no centro da cidade, criada como marco pela passagem do milênio e dos 500 anos do descobrimento do Brasil. Sua base possui cinco apoios, o corpo é um único bastão de ferro e a extremidade é uma cruz. Toda branca, de dia é possível visualizá-la por completo e de noite, quando o topo é aceso, transforma-se em farol. Na marca, a base perde profundidade, tornando-se bidimensional, e a cruz ganha um maior destaque na sua escala. Após a sua inauguração, o Luzeiro se transformou num local abandonado, não tendo alcançando seu objetivo de fazer parte do circuito turístico da cidade.

O Unique Condominium aparece curiosamente como um ícone na marca governamental. O prédio é um investimento empresarial na cidade e carrega uma arquitetura altamente moderna, formada por três torres no bairro Triângulo, sendo a mais alta com 27 andares. O edifício começou a ser construído em 2013 para conter um centro empresarial além de uma ala residencial. Quanto à aparição visual do Unique 


\section{VOZES $_{\text {\&DÁLORO }}^{\mid}$}

Itajaí, v. 17, n. 02, jul./dez. 2018

Condominium na marca da prefeitura, ela é representada de forma muito semelhante à fotografia do quadro. O Unique na representação da marca perdeu detalhes como cor, planos, profundidade e linhas. Ausências que são características da abstração.

O Memorial Padre Cícero se localiza no bairro Socorro. É uma fundação cujo objetivo é preservar e divulgar a memória do Padre Cícero. Fundado em 1988, o Memorial possui um acervo bibliotecário, um auditório, setor de exposição de utensílios do Padre, escritos, além do canhão usado na guerra da Sedição de Juazeiro. De arquitetura simples, com o traçado geométrico, o teto do lugar é uma cobertura na cor cinza, enquanto a base é quadrada e de material espelhado. Na logo permanece o formato de cobertura da arquitetura do lugar, mas a cor é alterada para o branco, simplificando forma, volume e linhas.

Por último, a Igreja de Nossa Senhora do Socorro é apresentada na marca da prefeitura. Localizada à frente do principal cemitério da cidade, no bairro Socorro, a Capela do Socorro, como é conhecida, data de meados de 1908 e é o lugar onde estão sepultados os restos mortais do Padre Cícero Romão Batista, sendo assim, considerada um dos principais locais sagrados e de grande visitação de Juazeiro. Por esses motivos, certamente, a Igreja do Socorro foi eleita para fazer parte dos ícones da marca governamental da "Terra do Padim", aparecendo representada pela mudança da cor (do amarelo para o branco), pela perda de linhas, volume e planos.

De modo geral, tais presenças na identidade visual da gestão municipal revelam a dinâmica da representação visual da cidade, que se pluraliza em ícones que são marcos visuais da paisagem urbana. Ainda que fortemente vinculada à figura de padre Cícero, o comparecimento de representações arquitetônicas é relevante para pensarmos que outra Juazeiro está sendo convocada à comunicação visual da cidade.

\section{Considerações finais}

A partir do presente estudo, exploramos a apropriação icônica da cidade de Juazeiro do Norte, que passa por elaborações sígnicas determinantes na identidade visual da gestão municipal. Uma vez que Padre Cícero divide espaço com outros ícones, é fundamental trazê-los à tona, pois entendemos que eles são valores que traduzem uma construção visual e simbólica dos desígnios da administração pública. Há uma indicação de quais elementos são relevantes para a representação de uma comunicação visual mnemônica da cidade.

A imagem da cidade de Juazeiro do Norte, por meio dos signos analisados, indica que o ciclo religião, arquitetura e desenvolvimento econômico estão imbricados na construção de uma imagem coletiva de "trabalho e fé". As arquiteturas do Memorial e da Igreja se destacam por uma ligação simbólica com Padre Cícero, ainda que este diálogo não se apresente diretamente para quem não conhece os locais. As formas modernas e 


\section{VOZES:}

Itajaí, v. 17, n. 02, jul./dez. 2018

retilíneas do Memorial, inclusive, elaboram uma aparência atual para a marca, que foge de um padrão já marcado por linhas curvas, como o formato da Igreja. O Luzeiro e o Unique Condominium se incluem nessa dinâmica de formas que contrastam com os lugares já mnemonicamente e popularmente representados.

Sobre o Unique Condominium, inclusive, vale ressaltar a discrepância de sentido dentre os cinco ícones. É o ícone que apresenta o mais sintomático desvio semântico da religiosidade e da figura do Padre Cícero. É um prédio empresarial, pertencente à construtora Base, o que comunica uma ligação público-privado da identidade visual da Prefeitura e, consequentemente, um diálogo entre propósitos da gestão atual com empresários. Esse entendimento faz com que observemos que a gestão pública da cidade busca representação no logro econômico e arquitetônico, não ficando desconectada dos padrões hegemônicos globais. Entra em jogo a reinvenção de uma imagem da cidade do interior do Nordeste brasileiro, que busca ser lembrada para além da figura popular de Padre Cícero, recorrendo a signos visuais da nova paisagem urbana.

\section{Referências}

ARAÚJO, Maria de Lourdes de. A cidade do Padre Cícero: trabalho e fé. Fortaleza: Editora IMEPH, 2011.

BARTHES, Roland. Elementos de semiologia. São Paulo: Cultrix, 2012.

BARTHES, Roland. Inéditos: Vol. III - Imagem e moda. São Paulo: Martins Fontes, 2005.

DONDIS, Donis A. Sintaxe da linguagem visual. São Paulo: Martins Fontes, 2003.

NETO, Lira. Padre Cícero: poder, fé e guerra no sertão. São Paulo: Cia. das Letras, 2009 . 